\title{
Legal Requirements for the Quality of Herbal Substances and Herbal Preparations for the Manufacturing of Herbal Medicinal Products in the European Union*
}

Authors

Affiliation
Arnold Vlietinck, Luc Pieters, Sandra Apers

Department of Pharmaceutical Sciences, University of Antwerp, Antwerp, Belgium
Key words

- herbal substance

- herbal preparation

- herbal medicinal product

quality

- European Pharmacopoeia

- European Medicines Agency

- Committee on Herbal Medicinal Products received Sept. 24, 2008

revised Nov. 17, 2008

accepted Nov. 24, 2008

\section{Bibliography}

DOI 10.1055/s-0029-1185307 Published online February 9 ,

2009

Planta Med 2009; 75: 683-688

(c) Georg Thieme Verlag KG

Stuttgart · New York .

ISSN 0032-0943

\section{Correspondence}

A. J. Vlietinck

Department of Pharmaceutical

Sciences

University of Antwerp

Universiteitsplein 1

2610 Antwerp

Belgium

Phone: + 3238202733

Fax: + 3238202709

arnold.vlietinck@ua.ac.be

\section{Abstract}

$\nabla$

In the European Union (EU) herbal medicinal products have become increasingly important. This is, for instance, underlined by the recent introduction of a simplified procedure in the Member States of the EU allowing the registration of herbal medicinal products which fulfill the criteria of a traditional herbal medicinal product, i.e., sufficient evidence of its medicinal use throughout a period of at least 30 years for products in the EU and at least 15 years within the EU and 15 years elsewhere for products outside the EU. With regard to the manufacturing of these products and their quality, applications of traditional herbal medicinal products have to fulfil the same requirements as applications for a marketing authorization. The quality of herbal substances as well as herbal preparations will be determined by the availabilty of modern science-based public monographs in the European Pharmacopoeia and their equivalents developed by the pharmaceutical industry. The standards put forward in these monographs must allow us not only to define the quality of these products, but also to eliminate dangerous counterfeit, substandard, adulterated and contaminated (traditional) herbal medicinal products. The usefulness of these monographs to implement the criteria on quality and specifications put forward for these products in the different guidelines of the European Medicines Agency (EMEA) is discussed.

\footnotetext{
${ }^{*}$ History: This article is based on a plenary lecture, presented by A.J. Vlietinck, as recipient of the Phytochemical Society of Europe Silver Medal at the 7th Joint Meeting of AFERP, ASP, GA, PSA and SIF in Athens on August 4, 2008.
}

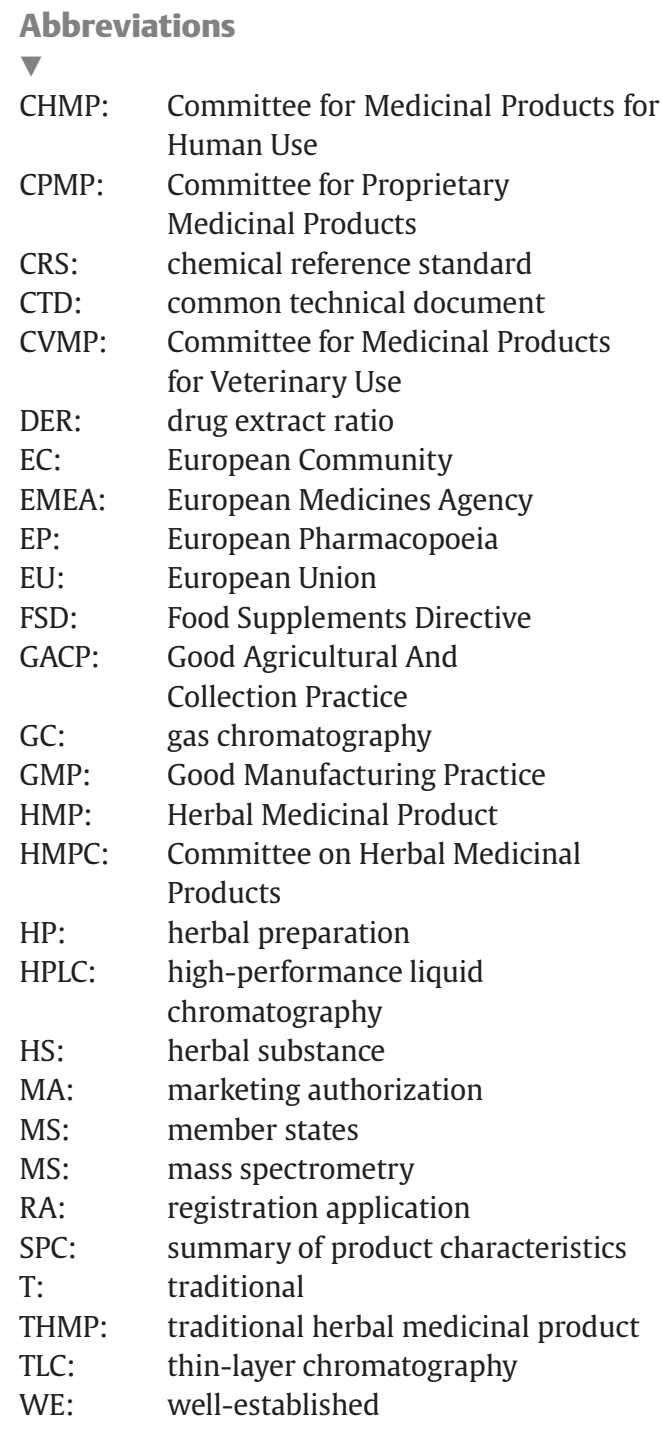

\section{Abbreviations}

CHMP: Committee for Medicinal Products for Human Us Medicinal Products

CRS: $\quad$ chemical reference standard

CTD: common technical document

for Veterinary Use

DER: drug extract ratio

EC: $\quad$ European Community

EMEA: European Medicines Agency

EP: $\quad$ European Pharmacopoeia

EU: $\quad$ European Union

FSD: $\quad$ Food Supplements Directive

Collection Practice

GC: gas chromatography

GMP: $\quad$ Good Manufacturing Practice

HMP: Herbal Medicinal Product 


\section{Introduction}

$\nabla$

Within the group of industrially-prepared herbal or botanical products there is a large variation in all of the member states (MS) of the European Union (EU) with regard to the properties and the legal status of these products. Some herbal products come closer to or are medicines, while others are close to or even identical to foods such as food supplements, novel foods, functional foods, etc. and still others are considered as cosmetics and medical devices. It is, therefore, not surprising that recently within the EU appropriate regulatory actions have been undertaken to regulate and harmonize the legal status of these various groups of plant preparations throughout the different European countries.

The EU has recently considered herbal products in several legislative texts [1]. Medicinal use has been harmonized for herbal medicinal products (HMP) with regard to well-established (WE) and traditional (T) uses through Directives 2004/27/EC and 2004/ 24/EC amending Directive 2001/83/EC [2-4].

Use of herbal preparations in unit dose form under food law is covered in the Food Supplements Directive (FSD) 2002/46/EC [5]. Regulations on nutrition and health claims and on the addition of vitamins and minerals and certain other substances to foods have been adopted on December 20, 2006 [6,7]. There are also specific authorization procedures for novel foods and cosmetics containing herbal ingredients. These procedures are part of the scope of regulation (EC) no. 258/97 and Council Directive 76/768/ECC, respectively $[8,9]$.

\section{European Authorization Procedures for Herbal Medicinal Products (HMP) \\ $\nabla$}

An overview of the existing EC market access for herbal medicinal products is shown in $\odot$ Table 1.

Medicinal products are defined by Dir 2004/27/EC as "any substance or combination of substances presented as having properties for treating or preventing disease in human beings; or any substance or combination of substances which may be used in or administered to human beings either with a view to restoring, correcting or modifying physiological functions by exerting a pharmacological, immunological or metabolic action, or to making a medical diagnosis".

Furthermore, Article 2.2 of said Directive also states that in cases of doubt, where taking into account all its characteristics, a product may fall within the definition of a "medicinal product" and within the definition of a product covered by other Community legislation the provisions of this Directive shall apply. This provision basically puts into legal text the jurisprudence that has been established over the years by the European Court of Justice on borderline cases.

All medicinal products including HMP may only be marketed in the EU when they have obtained a marketing authorization (MA) or a registration application (RA) by the competent authorities. The MA procedure requires the documentation of pharmaceutical quality, safety and efficacy, in addition to all other data concerning the medicinal product including name, pharmaceutical form, indication fields, dosage and risk information. Such an MA can be issued by the competent authority of a Member State (MS) of the EU for its own territory (national authorization) or can be granted in accordance with Regulation EEC no. 2309/93 for the entire community (community authorization) [10]. The
Table 1 Market access of herbal medicinal products in the EU.

$\begin{array}{ll}\begin{array}{l}\text { Herbal medicinal product } \\ \text { Marketing authorization (MA) }\end{array} & \text { EU legislation } \\ \begin{array}{l}\text { full application } \\ \text { bibliographic application }\end{array} & \text { Dir 2001/83/EC [2] } \\ \text { Well-established HMP } & \\ \text { mixed application } & \\ \text { Registration application (RA) } & \\ \text { simplified application } & \text { amended by Dir 2004/24/EC [4] } \\ & \text { Traditional Herbal Medicinal } \\ & \end{array}$

European centralized MA - obligatory for products derived from biotechnology and optional for technologically advanced products - which provides an MA for all MS of the EU at the same time is not applicable as yet to HMP. On the contrary, the European mutual recognition procedure is most important for HMP, because it provides for the extension of an MA granted by one MS to one or more identified by the applicant. Therefore, the competent authority having granted the initial MA should prepare an evaluation report, which can be accepted or refused by the other concerned MS. In the latter case an arbitration procedure might be started by the control authority according to which the MA is recognized or refused. Thus, in practice, it is possible that arbitration might result in the loss of an existing MA because different assessment criteria might exist in different MS. Therefore, harmonized assessment criteria for HMP to be applied by the different authorities are more than desirable $[11,12]$.

An MA of HMP cannot only be granted upon applications based on a full documentation with new tests and trials on safety and efficacy, but also "bibliographic applications" for well-established (WE) HMP are allowed for MA. As described in Art. 10a of Directive 2001/83 as amended, the results of preclinical tests or clinial trials are not required if it can be demonstrated that the active substances of the HMP have been in well-established medicinal use within the EU for at least 10 years, with recognized efficacy and an acceptable level of safety in terms of the conditions set out in Annex I of that Directive. The detailed scientific bibliography shall address non-clinical and clinical characteristcs as described in the guidelines developed by the Committee on Herbal Medicinal Products (HMPC) of the European Medicines Agency (EMEA) $[13,14]$. If these minimum requirements cannot be fulfilled by published literature, additional non-clinical tests may be necessary, then resulting in a "mixed application".

Through the Directive on Traditional Herbal Medicinal Products (THMP) a further group on HMP has been established within the European regulatory framework. This Directive which entered into force on 30 April 2004 provides an area below the WE medicinal use area comprising those HMP with minor claims, designed for use without supervision of a medical practitioner, defined strength and posology, limited methods of administration which are of sufficient pharmaceutical quality and proven safety. The efficacy should be plausible on the basis of long-standing use and experience. The period of traditional use should be at least 30 years within the EU, products from outside the EU must prove at least 15 years within Europe and 15 years outside Europe. The Directive is also eligible for combinations of HMP and vitamins and minerals may be added if their action is ancillary to that of the herbal active constituent(s) $[4,15]$. The MS had to comply with this Directive by 30 October 2005. For THMPs that were already 
on the market on the entry into force of this Directive, the competent authorities shall apply the provision of the Directive within 7 years after this entry into force, viz. 30 April 2011.

By the introduction of the Directive on THMP there exists formally a "dual system" allowing one to market an HMP with a "well-established medicinal use" based on bibliographic data and/or clinical studies or as a "traditional HMP" with reference to long-term use and experience [12].

\section{The Committee on Herbal Medicinal Products (HMPC) and its Role in the World of Quality of (T)HMP \\ $\nabla$}

In addition, Directive 2004/24/EC provided the establishment of the new committee of HMP (HMPC) within the EMEA consisting of one representative and one alternate member from each MS in addition to five co-opted members, who are selected on the basis of their specific scientific competence in well-defined areas.

In this way, the former HMP Working Party (HMPWP) was upgraded to the status of the other EMEA Committees. The HMPC has the task of establishing community herbal monographs for WE MA and registrations of THMP and of setting up a European list on herbal substances (HS), herbal preparations (HP) and combinations thereof for use in THMP. This Committee has consequently comprehensive competence with regard to the assessment of HMP on a European level.

Up till now the HMPC has elaborated a number of guidance documents, which are important for the assessment of quality, safety and efficacy of (T)HMP.

The guidelines on quality and specifications of HMP/THMP have been published after revision (CPMP/QWP/2819/00 Rev 1 or EMEA/CVMP/814/00 Rev 1 and CPMP/QWP/2820/00 Rev 1 or EMEA/CVMP/815/00 Rev 1) [16,17]. The existing Points to Consider Document on "Good Agricultural and Collection Practice (GACP) for starting materials of herbal origin" has been revised and published as a guideline (EMEA/HMPC/246816/2005). Guideline on the declaration of HS and HP in HMP/THMP in the SPC (Summary of Product Characteristics) and on the use of the CTD (Common Technical Document) format in the preparation of a registration application for THMP (EMEA/HMPC/CHMP/ CVMP/287539/2005 and EMEA/HMPC/71 049/2007) are important since their use will contribute to a correct and uniform introduction of applications on (T)HMP in Europe.

The guideline on quality of combination HMP/THMP has been finalized in June 2008 (EMEA/HMPC/CHMP/CVMP/214869/2006). It includes pragmatic approaches for identification and quantitative determination of herbal preparations in combination products and takes into account their complex composition. Moreover, putative solutions are given in case identification and/or quantitative determination of an active substance cannot be performed in the finished product. There is no expectation that existing HMPs on the market will be affected by the abovementioned guidelines, with the exception of THMPs for human use that were already on the market on the entry into force of Dir 2004/24/EC (30 April 2004) for which competent authorities shall apply the provisions of Dir 2004/24/EC within seven years of its entry into force. For any new MA application, these guidelines are applicable. These guidelines are also applicable to any traditional use (human) registration application submitted after 30 October 2005, by when MS shall comply with Dir 2004/24/EC. Some reflection papers have also been finalized, e.g., on the use of fumigants (EMEA/HMPC/125562/2006) and on markers used for quantitative and qualitative analyses of HMP/THMP (EMEA/ HMPC/253629/2007).

All these guidelines offer an important legal framework to help manufacturers to improve the quality of their T(HMP). Reproducible quality of (T)HMP is indeed the basis of reproducible safety and reproducible efficacy, which finally determines the risk benefit ratio of these drugs $[18,19]$.

\section{The European Pharmacopoeia and its Role in the World of Quality of (T)HMP}

The European Pharmacopoeia (EP) comprises two groups of experts on phytochemistry, who elaborate monographs on herbal drugs and herbal drug preparations (groups 13A and 13B). Since 2007 a special working group has been started with the elaboration of monographs on traditional Chinese plants and preparations (TCM group).

An overview of the number of monographs on these products, taken up in the 6th edition of the EP is given in $\bullet$ Table 2 [20].

This impressive number of monographs on plant products shows the interest of the EP authorities for a harmonized development of (T)HMP throughout Europe. For this reason, a close relationship is maintained with the HMPC at the EMEA through a mutual observership.

The EP also published nearly 250 general methods on analysis and introduced a certification of suitability to the monographs of the EP. This certification procedure was also made applicable to herbal drug preparations in March 2003, but unfortunately no dossiers have been introduced as yet.

The EP is also working assiduously through a Pharmacopoeial Discussion Group (PDG) together with the Japanese and US Pharmacopoeias for harmoniztion at world level [21].

\section{Pharmaceutical quality assurance of (T)HMP:}

herbal substance and herbal preparation

In case of (T)HMP, the herbal substance, i.e., the starting plant material and/or the herbal preparation, i.e., the plant extract, tincture, exsudate, fatty oil, essential oil, etc. represent the active substance. Therefore, the quality of the herbal active substance must be asssured in such a way that consistent therapeutic success is guaranteed from batch to batch. A main prerequisite is a reproducible spectrum of constituents [22].

Consequently the quality of the (T)HMP will largely depend on the quality of the herbal substance, the manufacturing procedure of the herbal preparation from the plant material and the manufacture of the (T)HMP from the herbal preparation. Development, in-process controls, GACP and GMP (good manufacturing prac-

Table 2 Number of monographs in the EP on plant products (until June 2008).

\begin{tabular}{|llll|}
\hline Plant products & $\begin{array}{l}\text { Pub- } \\
\text { lished }\end{array}$ & $\begin{array}{l}\text { Under } \\
\text { study }\end{array}$ & Total \\
\hline $\begin{array}{l}\text { Herbal drugs* (= herbal substances) } \\
\text { Herbal drug preparations* } \\
\text { (herbal preparations) }\end{array}$ & 166 & 38 & 204 \\
\hline extracts, tinctures, essential oils & & & \\
\hline fatty oils, waxes, starches & 77 & 17 & 94 \\
\hline Total & 28 & - & 28 \\
\hline
\end{tabular}

* Herbal drugs and herbal drug preparations are terms used in the EP for herbal substances and herbal preparations of the EMEA. 


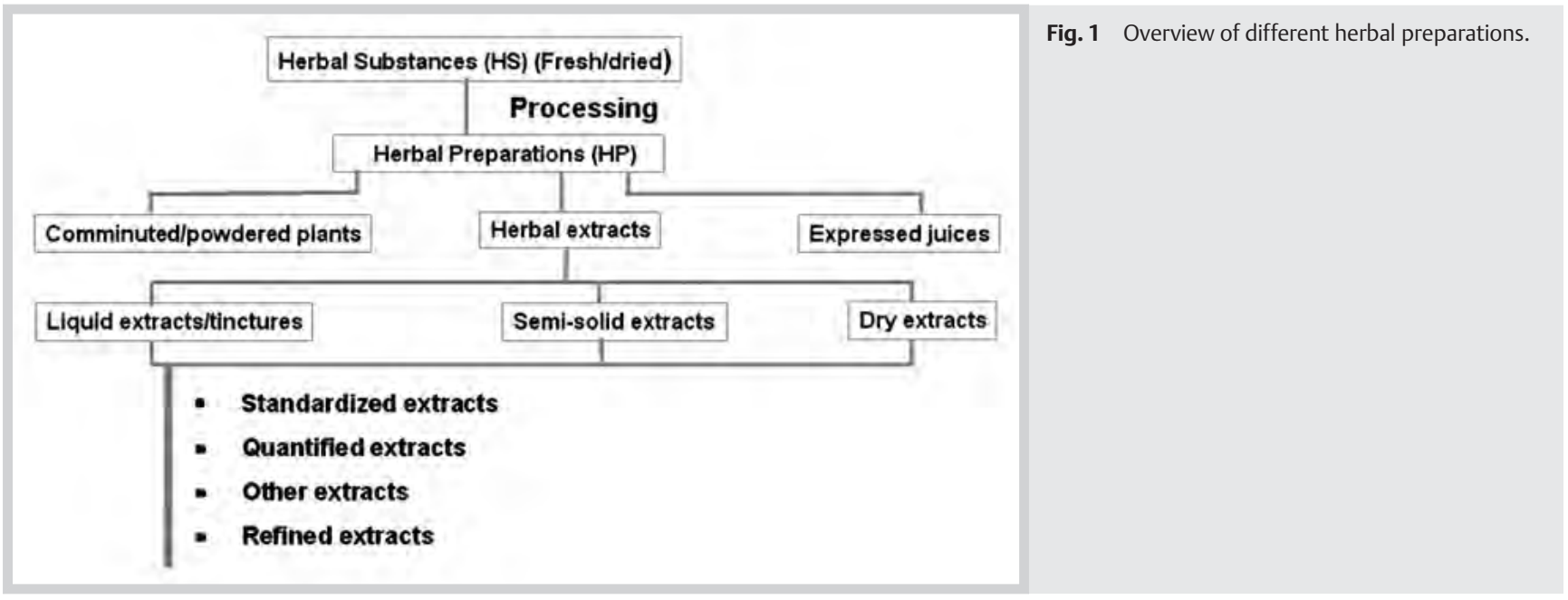

tice) controls and process validation according to the specifications put forward in the guidelines of the EMEA are necessary to ensure consistent production of herbal substances/preparations and (T)HMP of high quality.

\section{Quality of herbal substances through controlled cultivation}

In contrast to chemically defined substances, starting plant materials are regularly subject to considerable natural variabilities as regards the content of active and concomitant substances as well as contaminations of different origin. Not only genetic factors such as chemical races but also growing conditions such as climate, soil quality and pests affect the spectrum of constituents and hence the quality of the plant material. Furthermore, harvesting and drying conditions, pre- and post-harvest treatments with pesticides and fumigants, and comminuting and storage conditions are further factors influencing the quality of the herbal substance.

Cultivation and breeding investigations mainly focus on optimizing the active constituents and reducing the putatitve contaminations and on the improvement of harvesting and drying conditions. Cultivation is sometimes the ultimate solution of obtaining sufficient amounts of species that are listed as endangered. It is clear that collection must not damage the growth environment ensuring optimum conditions for regeneration of the herbal substance harvested.

Characterization of herbal substances includes a detailed evaluation of all botanical and phytochemical aspects of the plant and comprises identification and purity tests as well as an assay. Macroscopic and microscopic identification should be done according to the requirements of the monographs of the EP. If no such monograph is available, a comprehensive specification for the herbal substance must be supplied and set up in the same way as the monograph in the EP. Phytochemical identification and assay of the herbal substance might be analogous to those of the corresponding herbal preparation and consist of a chromatographic fingerprinting and a quantitative determination of certain constituents. With respect to assaying three types of herbal substances have to be distinguished viz. (1) herbal substances with constituents with known therapeutic activity, (2) those with known active constituents (active markers) and (3) herbal substances where constituents with known therapeutic activity or active markers are not known.
Besides the normal purity tests included in the monographs of the EP, herbal substances have to meet additional purity requirements due to their natural origin. These requirements are, e.g., tests for heavy metals, residues of pesticides, fumigants, residual solvents, mycotoxins and microbial contaminants. Radioactivity should be tested if there are reasons for concern.

\section{Quality of herbal preparations through controlled manufacture}

Besides the quality of the herbal substance, the manufacturing process has an essential impact on the quality of a herbal preparation. In order to reproduce a defined quality profile, the individual extraction steps have to be determined and specified. Besides comminuted or powdered plant (parts) and expressed juices, respectively, prepared from dried and fresh herbal substances, herbal preparations consist of herbal extracts, which can be distinguished in different types according to their physical state. The EP basically defines liquid preparations (extracta fluida, tincturae), semi-solid or soft preparations (extracta spissa) and dry preparations (extracta sicca). An overview of the different types of extracts is given in $\bullet$ Fig. 1.

In general, dry extracts are powdered substances obtained by complete evaporation of the extraction solvent. They are often used in the formulation of solid and semi-solid herbal medicinal products. Soft extracts are highly viscous preparations obtained by partial evaporation of the extraction solvent. Due to their low stability and their susceptibility to microbial growth, they have been replaced almost completely by dry extracts. Liquid extracts and tinctures are liquid preparations with the extraction solvent remaining in the extract. Differentation is made with regard to the ratio of the herbal substance to the extraction solvent. Liquid extracts are obtained from extracting 1 part of the plant with 1-2 parts of the solvent, whereas for tinctures 1 part of the plant has been extracted with 5 or 10 parts of the solvent. These preparations are often used directly as semi-solid (ointments) or liquid dosage forms (drops, solutions).

For a correct understanding of the scope of the definition relating to processed plant materials, it is necessary to distinguish between native herbal preparations ("genuine") which consist solely of genuine extractable matter and not native herbal preparations, which contain also inert excipients such as extraction solvents (e.g., water, alcohol, vegetable oil) or excipients (e.g., maltodextrins, lactose, saccharose, silicon dioxide), needed for process- 
ing, standardization or technical reasons such as physical stability of the extracts. Both types of extracts are covered by the definition of the EP [22].

Depending on the intended type of extract, the defined comminuting of the herbal substance is followed by extraction and, if applicable, evaporation, concentration and standardization or quantification of the extract. Each of the manufacturing steps should be validated in order to lead to a reproducible extract quality within certain defined specification limits. Furthermore, control tests in the individual production steps play a significant role in the manufacture of herbal extracts and their quality assurance.

The ratio of the herbal substance to the native herbal preparation, i.e., the drug extract ratio or DER is an important criterion for the characterization of a herbal preparation.

The DER native is the ratio of the mass of the starting material (herbal substance) to the mass of the resulting native extract (herbal preparation). The mass of the native herbal preparation is equal to 1 , e.g., a $\operatorname{DER}_{\text {native }} 2: 1$ means that 2 parts of the herbal substance are needed to obtain 1 part of native herbal preparation. Thus the DER native is the reciprocal value of the quantity of extractable matter that is obtained with a defined extraction solvent and a validated extraction procedure, i.e., $50 \%$ of the extractable matter in this case [22].

The ratio of the herbal substance in the extract preparation is the ratio of the mass of herbal substance to the mass of the not-native extract including the native extract as well as the extraction solvent or residues of it and/or added excipients. In contrast to dry extracts, which are characterized in the label by the DER ${ }_{\text {native, }}$, the label of liquid and soft extracts contains the DER, i.e., the ratio of the starting material to the extract preparation, e.g., tincture $1: 5$, means that 1 part of herbal substance results in 5 parts of the tincture.

The quantity and the composition of the native extract and the $D^{D E R} R_{\text {native }}$ are mainly influenced by the following parameters, (1) starting herbal substance, (2) extraction solvent, (3) manufacturing procedure, and (4) manufacturing apparatus [22].

\section{Classification of extracts in the EP}

The EP introduced new definitions which classify extracts into three categories depending on the presence of constituents with known therapeutic activity or further relevant constituents [23] (O Fig. 1).

Standardized extracts are adjusted within an acceptable tolerance to a given content of constituents with known therapeutic activity; standardization is achieved by adjustment of the extract with inert material or by blending batches of extracts. The amount of the native extract may then vary. Consequently, the quantity of the genuine preparation shall be given as a range corresponding to a defined quantity of constituents with known therapeutic activity, e.g., Senna leaf extract standardized: 50$65 \mathrm{mg}$ corresponding to $12.5 \mathrm{mg}$ of hydroxyanthracene glycosides calculated as sennoside B (EMEA/CVMP/814/00 Rev 1).

Quantified extracts are adjusted to a defined range of constituents (active markers); adjustments are exclusively achieved by blending batches of extracts. Consequently, the quantity of the genuine herbal preparation has to be stated as a distinct content and the content of the quantified substance(s) shall be specified in a range, e.g., Ginkgo leaf extract quantified: $60 \mathrm{mg}$ containing 13.2-16.2 mg flavonoids expressed as flavone glycosides, 1.68 - $b<2.04 \mathrm{mg}$ ginkgolides A,B and C and 1.56-1.92 mg bilobalide.
Other extracts are herbal preparations for which the (therapeutically) active consituents are not known. These extracts are not adjusted to a defined content of analytical markers. They are essentially defined by their production process and their specifications. In this case, the quantity of the genuine herbal preparation shall be stated as a distinct content, e.g., Valerian dry extract ethanolic $60 \%(\mathrm{v} / \mathrm{v}): 125 \mathrm{mg}$. For the analytical definition of the amount of the native extract an analytical marker can be chosen by the manufacturer, if not defined in the corresponding Pharmacopoeia monograph.

If, during the production of standardized or quantified extracts, purification procedures have been applied that increase the proportions of characterized constituents in the extractable matter with respect to the expected values, the EP refers to such an extract as "refined", e.g., Ginkgo leaf extract, quantified and refined.

\section{Quality control of herbal substances and/or herbal} preparations through modern analytical methods Since plant preparations are often considered to be active in their entirety, such mixtures of constituents must be identified by a semiquantitative proof of content, i.e., a chromatographic fingerprint as well as by a useful assay of the characteristic constituents.

Identification tests should be specific and optimally also discriminating with regard to substitutes and adulterants that are likely to occur. Identification solely by chromatographic retention times, for example, is not regarded as being specific. A combination, however, of chromatographic tests such as high-performance liquid chromatography (HPLC) and thin-layer chromatographic (TLC) densitometry or a combination of tests into a single procedure such as HPLC/ultraviolet (UV)-diode array, HPLC-mass spectrometry (MS), or gas chromatography (GC)-MS may be acceptable. These hyphenated techniques do indeed facilitate a selective analysis of the plant constituents in many cases also directly from their natural matrix.

The quantitative analysis of herbal substances and/or herbal preparations claims an exceptional position as compared to their synthetic counterparts because plant constituents are mixtures of various components embedded in a natural matrix. Consequently, the sample preparation for analysis of these products will mostly require complex processing because the substances to be analyzed often have to be separated from a matrix which is subject to natural variations. This procedure implies further sources of error and thus requires larger standard deviations of the methods than the analytical tests of chemically defined active substances. Moreover, due to the frequent absence of selective analytical methods, nonspecific assays should be applied in such cases, e.g., colorimetric determination of saponins or photometric determination of flavonoids.

Nevertheless, the analytical procedures applied to quantify (the groups of) active substances or markers must be validated by analogy with preparations with chemically defined active substances. The analytical method validation aims at proving and documenting that an analytical method is reliable and acceptable for its intended purpose. In general, the developer or user of the method generates evidence on linearity range, specificity, accuracy, precision, detection and quantification limits and robustness of the method for regulatory submissions or in-house application [24].

For qualitative and quantitive analysis of constituents in herbal substances and/or herbal preparations reference standards are needed to verify the results of the testing. The number of refer- 
ence standards in the EP is quite impressive, but there are only a few for herbal products among them. Thus, in most cases, the reference standards have to be either procured commercially or isolated and documented on an individual basis. Nowadays, more and more plant products are introduced as chemical reference standards (CRS) in the EP. These reference standards established for the determination of the content of constituents in herbal substances and/or herbal preparations may be the active constituents themselves, marker constituents used for quantification or plant extracts. The reference standards consisting of extracts are established using well-characterized samples of active constituents or markers. Examples of CRS plant components are boldine (boldo leaf), ruscogenins (butcher's broom) and aescin (horse chestnut dry extract). Examples of reference standards consisting of extracts are milk thistle standardized dry extract CRS and Agnus castus fruit standardized dry extract CRS. The choice between pure plant compounds or extracts as CRS depends on availability, cost price and stability. It should be noticed that all reference substances will have assigned contents, so that the assignment of content of the CRS should no longer be done by the user.

\section{Conclusions}

$\nabla$

It has been shown that quality requirements should be the same for all herbal medicinal products, irrespective of whether these products have obtained a marketing authorization or a registration. Quality of herbal medicinal products applies from the field (herbal substance) through the manufacture of the active substance (herbal preparation) and to the finished product [(T)HMP]. Consequently, quality is inherent to the product and not just tested into it.

The new European legislation in the areas of well-established and traditional uses open up new prospects for (T)HMP on the European level. It promotes a single market for these drugs by introducing consistent standards and procedures and by encouraging cross-border trade of them. Unfortunately, knowledge on the active constituents of many plant products still needs to be improved and therefore further research in pharmacognosy and phytotherapy is urgently needed. It will then be up to pharmaceutical entrepreneurs to take advantage of these new findings on (T)HMP to market them in as many as possible European countries.

\section{References}

1 European Union Law website. Available at: http://eur-lex.europa.eu/en/ index.htm. Accessed September 5, 2008

2 Directive 2001/83/EC of the European Parliament and of the Council of 6 November 2001 on the Community Code relating to medicinal products for human use. Official Journal of the European Union: L311/67; 28 November 2001: 67-128

3 Directive 2004/27/EC of the European Parliament and of the Council of 31 March 2004 amending Directive 2001/83/EC on the Community Code relating to medicinal products for human use. Official Journal of the European Union: L136/34; 30 April 2004: 34-57

4 Directive 2004/24/EC of the European Parliament and of the Council of 31 March 2004 amending as regards traditional herbal medicinal products, Directive 2001/83/EC on the Community Code relating to medicinal products for human use. Official Journal of the European Union: L183/51; 30 April 2004: 85-90

5 Directive 2002/46/EC of the European Parliament and of the Council of 10 June 2002 on the approximation of the laws of the Member States relating to food supplements. Official Journal of the European Union: L183; 12 July 2002: $51-57$
6 Council Regulation (EC) No 1924/2006 of the European Parliament and the Council of 20th December 2006 on nutrition and health claims made on foods. Official Journal of the European Union: L404/9; 30 December 2006: 9-25

7 Council Regulation (EC) No 1925/2006 of the European Parliament and of the Council of 20th December 2006 on the addition of vitamins and minerals and of certain other substances to foods. Official Journal of the European Union: L404/26; 30 December 2006: 2638

8 Regulation (EC) No 258/97 of the European Parliament and of the Council of 27 January 1997 concerning novel foods and novel food ingredients. Official Journal of the European Union: L043/1; 14 February 1997: 1-6

9 Council Directive 76/768/EEC of 27 July 1976 on the approximation of the laws of the Member States, relating to cosmetic products. Official Journal of the European Union: L262; 27 September 1976: 169-200

10 Council Regulation 2309/93 EEC of the European Parliament and of the Council of 22 July 1993. Laying down community procedures for the authorisation and supervision of medicinal products for human and veterinary use and establishing a European agency for the evaluation of medicinal products. Official Journal of the European Union: L214; 24 August 1993: 1-31

11 Benzi G, Ceci A. Herbal medicines in European regulation. Pharmacol Res 1997: 35; 355-362

12 Steinhoff B, Sagel A, Küpper SD. Herbal medicinal products in Germany: scientific knowledge and regulatory framework. 2nd English edition. Bonn: Bundesverband der Arzneimittel-Hersteller e.V.; 2008: 1-37

13 EMEA Committee on Herbal Medicinal Products (CHMP). Guideline on non-clinical documentation for herbal medicinal products in applications for marketing authorization (bibliographic and mixed applications) and in applications for simplified registration. EMEA/HMPC/ 32116, 13 July 2006, Available at http://www.emea.europa.eu/htms/ human/humanguidelines/nonclinical.htm. Accessed September 5, 2008

14 EMEA Committee on Herbal Medicinal Products (CHMP). Guideline on the assessment of clinical safety and efficacy in the preparation of monographs for well-established and of monographs/lists for traditional herbal medicinal products/substances/preparations, EMEA/HMPC/104613/2005, 7 September 2006. Available at http:// www.emea.europa.eu/htms/human/humanguidelines/efficacy.htm. Accessed September 6, 2008

15 Silano M, De Vincenzi M, De Vincenzi A, Silano V. Commentary: the new European legislation on traditional herbal medicines: main features and perspectives. Fitoterapia 2004; 75: 107-116

16 EMEA Committee on Herbal Medicinal Products (CHMP) and Committee on Medicinal Products for Veterinary Use (CVMP). Guideline on quality of herbal medicinal products/traditional herbal medicinal products, CPMP/QWP/2819/00 Rev 1 or EMEA/CVMP/814/00 Rev 1, 30 March 2006. Available at http://www.emea.europa.eu/htms/human/humanguidelines/quality.htm. Accessed September 6, 2008

17 EMEA Committee on Herbal Medicinal Products (CHMP) and Committee on Medicinal Products for Veterinary Use (CVMP). Guideline on Specifications: Test Procedures and Acceptance Criteria for Herbal Preparations and Herbal Medicinal Products/Traditional Herbal Medicinal Products, CPMP/QWP/2820/00 Rev 1 or EMEA/CVMP/815/00 Rev 1, 30 March 2006. Available at http://www.emea.europa.eu/htms/human/humanguidelines/quality.htm. Accessed September 6, 2008

18 Bauer R. Quality criteria and standardization of phytopharmaceuticals : can acceptable drug standards be achieved? Drug Inform J 1998; 32: $101-110$

19 Busse $W$. The significance of quality for efficacy and safety of herbal medicinal products. Drug Inform J 2000; 34: 15-23

20 European Directorate for the Quality of Medicines \& Health Care. European pharmacopoeia. Available at http://online.edqm.eu/entry.htm. Accessed September 8, 2008

21 Artiges $A$. The role of pharmacopoeias in international harmonisation. J Pharm Biomed Anal 2001; 24: 769-772

22 Gaedcke F, Steinhoff B. Herbal medicinal products. Stuttgart: Medpharm Scientific Publishers, CRC Press; 2003: 37-65

23 [no authors listed]. European Pharmacopoeia. 6th edition, Vol.6.1. Strasbourg: Council of Europe; 2007: 3343-3344

24 Chandron S, Singh RSP. Comparison of various international guidelines for analytical method validation. Pharmazie 2007; 62: 1-14 